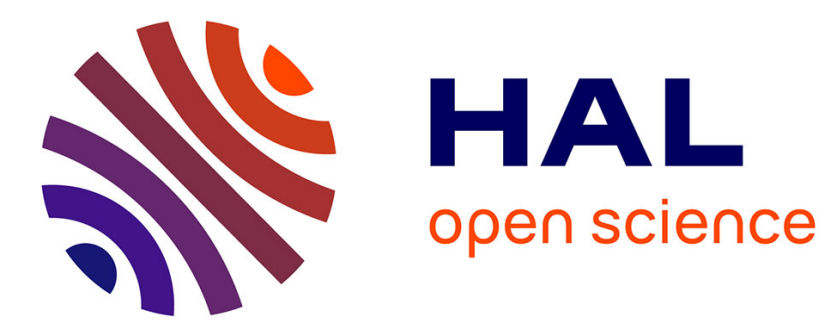

\title{
Noninvasive Gene Electrotransfer in Skin
}

Lise Pasquet, Sophie Chabot, Elisabeth Bellard, Marie-Pierre Rols, Justin

Teissié, Muriel Golzio

\section{To cite this version:}

Lise Pasquet, Sophie Chabot, Elisabeth Bellard, Marie-Pierre Rols, Justin Teissié, et al.. Noninvasive Gene Electrotransfer in Skin. Human gene therapy methods, 2019, 30 (1), pp.17-22. 10.1089/hgtb.2018.051 . hal-02390778

\section{HAL Id: hal-02390778 \\ https://hal.science/hal-02390778}

Submitted on 19 Mar 2021

HAL is a multi-disciplinary open access archive for the deposit and dissemination of scientific research documents, whether they are published or not. The documents may come from teaching and research institutions in France or abroad, or from public or private research centers.
L'archive ouverte pluridisciplinaire HAL, est destinée au dépôt et à la diffusion de documents scientifiques de niveau recherche, publiés ou non, émanant des établissements d'enseignement et de recherche français ou étrangers, des laboratoires publics ou privés. 


\section{Non-invasive gene electrotransfer in skin}

Pasquet Lise, Chabot Sophie, Bellard Elisabeth, Rols Marie-Pierre, Teissie Justin, Golzio Muriel.

Institut de Pharmacologie et de Biologie Structurale, Université de Toulouse, CNRS, UPS, BP 64182, 205 Route de Narbonne, F-31077, France

† Corresponding author: Justin Teissie; IPBS CNRS, UMR 5089, 205, Route de Narbonne, 31077 Toulouse Cedex, France; Telephone: +33(0)561175812, Fax: +33(0)561175994, Email: justin.teissie@ipbs.fr

Short title: ID GET 
ABSTRACT

The skin is considered as well suited for gene therapy and vaccination. DNA vaccines elicit both broad humoral and cellular immune responses when injected in the skin. Physical and chemical methods are needed to boost the expression. Gene electrotransfer (GET) is one of the most effective approaches. This step by step protocol describes the procedures to get an efficient GET targeted to the skin by using easy-to-use non-invasive electrodes after intradermal plasmid injection (ID GET). A specific pulse sequence is reported. Expression is observed by in vivo fluorescence imaging during more than 2 weeks as the plasmid was coding for tdtomato. The protocol is efficient for the transient expression of clinical proteins.

\section{KEYWORDS}

Gene transfer, Electroporation, skin 
INTRODUCTION.

The skin is not only a protective barrier that shields the body from external pathogenic agents. This organ is considered as well suited for gene therapy and vaccination, due to its accessibility, large surface area and the presence of numerous immune cells such as dendritic and Langerhans cells that can elicit appropriate immune responses ${ }^{1,2}$.

DNA vaccines have been shown to elicit both broad humoral and cellular immune responses when injected in the skin ${ }^{3}$. However, due to the barrier properties of the skin, the cellular penetration of DNA and resulting applications of skin DNA immunization are limited. Several chemical, biological and physical methods have been implemented to enhance skin DNA delivery (see for review ${ }^{4}$ ). The highly efficient viral gene transfer presents several side effects such as generation of novel infectious agents due to the risk of generating replication competent virus, immunogenicity of the vector and mutational insertion of viral DNA. Safe non-viral gene transfer approaches should be used where gene electrotransfer (GET) appears as the most promising ${ }^{1}$.

The structural morphology of mouse skin displays successive layers: stratum corneum (cornified dead cells), epidermis (epithelium), dermis (connective tissue) and hypodermis (adipose tissue). The epidermis is a stratified, squamous epithelium layer. The epidermis composed mainly of keratinocytes contains dendritic cells and Langerhans cells, involved in the immune system. The hypodermis fat also has immune-modulatory functions, and macrophages within adipose tissue should be considered as antigen-presenting cells ${ }^{5}$. Gene transfer can transfect adipocytes within the hypodermis, but most transfected cell types were in the dermis and epidermis ${ }^{6}$. Therefore, skin appeared to be a good target for immunization with an easy access ${ }^{7,8}$.

Skin gene electrotransfer (GET) is obtained by a local intradermal injection of a small volume of a plasmid solution followed by electrical voltage pulses delivery between electrodes in contact with the skin (ID GET). GET results from an electrophoretic driven accumulation of the plasmid ( $\mathrm{pDNA}$ ) towards the surface of the target cells, that are electropermeabilized ${ }^{9}$. The electric parameters that control the pDNA electrophoretic drift 
in the tissue and the level of target cell membrane permeabilization should be selected to preserve the cell viability ${ }^{10}$.

A complex pulse sequence (so called HV LV) where a short high field pulse (to trigger membrane permeabilization) is followed by a long low field pulse (to electrophoretically push the plasmid towards the permeabilized surface) is considered as the most effective to obtain a high level of expression ${ }^{11}$. This sequence has to be optimized for each cell system as the cell viability must be preserved. The total production of the transgene is controlled by the tissue volume that is affected. This volume is under the dependence of the electrode design. For dermal GET, the field distribution must focus its high value only in the thin layer of the skin. This is obtained by non-invasive electrodes in contact with the skin as the stratum corneum is permeabilized within microseconds, and its contribution to the field distribution in the skin tissue becomes negligible ${ }^{12}$. Several electrode models have been described. The skin can be pinched between plated electrodes and the field is across the skin and the tissue underneath, where expression is detected ${ }^{13}$. An array of small rod-shaped electrodes (multi-electrode array (MEA)), in contact with the skin brought a pattern of localized expression. Transgene-expressing cells were observed exclusively in the epidermal layer of the skin due the very localized field distribution ${ }^{14-16}$. The surface intradermal EP (SEP) device where the electrodes are minimally invasive brings expression deeper in the skin ${ }^{6}$.

We introduce a different approach with contact electrodes where the field is focused along the skin and where a large skin volume can be positively electropermeabilized ${ }^{17}$. This approach was used for electroimmunization in anti-angiogenesis developments ${ }^{18}$. We optimize the pulse protocol for this set of contact electrodes for ID GET by using a more sophisticated pulse generator. A reporter gene coding for a fluorescent protein allowed a quantified follow-up by using animal imaging. Histological investigation of the pulsed skin shows no damage in the tissue. 
MATERIALS

Sterile phosphate-buffered saline (PBS) pH 7.2. (Gibco, Thermofischer)

Plasmids adjusted at $1 \mathrm{mg} / \mathrm{ml}$ in sterile PBS (see Troubleshooting 1).

Prepare $1 \mathrm{ml}$ per animal plus $10 \%$ to compensate the loss when filling the syringes.

Hair removal lotion (Veet, France)

Ethanol $70 \%$.

Sterile syringes with needle $29 \mathrm{G} \times 1 / 2$ in (Terumo)

B-10 electropulsator (Betatech, St Orens, France)

Contact electrodes ${ }^{17}$.

Gel for electrodes (Comepa, St Denis, France)

Pico oscilloscope 2000 serie, ( Picoscope St Neots, UK)

Current clamp EN3 (Chauvin Arnoux, Paris, France)

Fluorescence Macroscope (Leica, Wetzlar, Germany) with a cooled CCD camera (Roper, USA)

MICE:

Animal studies are conducted in accordance with the principles and procedures outlined by the European convention for the protection of vertebrate animals used for experimentation.

Female C57BI/6 mice 6 to 9 weeks old were obtained from Janvier laboratory (Le Genest St. Isle, Saint Berthevin, France) (see troubleshooting 1) 
PLASMIDS:

pCMV-tdTomato Vector is a $5.4 \mathrm{~kb}$ plasmid DNA coding for tdTomato fluorescent protein (from Clontech, Mountain View, CA), amplified in Escherichia coli DH5 $\alpha$ and purified with the Maxiprep DNA Purification System (Qiagen, Germany) according to the manufacturer's protocol (see troubleshooting 2).

\section{EXPERIMENTAL PROCEDURE}

\section{Intra-dermal DNA injection:}

Hair on the back is removed with a hair removal lotion (Veet, France) 2 days before each electro-transfection. Skin inflammation may result from using razor rather than cream.

Animals are kept under isoflurane/air anesthesia during the whole procedure. The comfort of the lab animal is very important and it should not be stressed. Gas anesthesia is therefor better than chemical injection approaches. Anesthetize the mouse in a closed box with $4 \%$ isoflurane under a high flow rate $400-500 \mathrm{ml} / \mathrm{min}$ to make it deeply asleep quickly. This is obtained within about $1 \mathrm{~min}$. The closed box can be opened (under a hood if possible). You can then manipulate the mouse and transfer it on the electropulsation stage (see trouble shooting 8) with an inhalation mask where a lower flow (200-250 ml/min) of isoflurane at a lower dose (2\%) is continuously delivered during the GET experiment (18). Clean the naked skin with ethanol $70 \%$.

Mice are injected in two sites with $25 \mu \mathrm{g}$ of plasmid in $25 \mu \mathrm{l}$ PBS by intra-dermal (ID) route using a $300 \mu$ l syringe with a $29 \mathrm{G}$ needle (Terumo, France) (Fig.1). The injection should take no less than 5 seconds to avoid hemolytic transfection (see troubleshooting 3 ).

A mark with a permanent ink can clearly indicate the area of the skin where the injection was performed. 


\section{Electric pulses delivery}

Animals are kept under gas anesthesia.

We used non-invasive wire contact electrodes designed to focus the field in the tissue layer close under the skin between the wires (Fig.3). Treated skin surface is $0.5 \mathrm{~cm} 2$.

Apply conducting gel (Comepa, St Denis, France) on the edge of the electrodes to ensure good electrical contact with the skin surface. The gel should be present only on the electrodes and should not build a short-circuiting bridge between them (see troubleshooting 4). Hair removal prevents short circuits along the hairs.

Place the electrodes so that the bleb on the skin (see Troubleshooting 3 ) is between their two contacts with the skin.

Hold the contact electrodes firmly against the skin as a muscle contraction is present during the pulse delivery.

Following ID injection of plasmid DNA, an electrical field pulse train is applied on each injection site with $10 \mathrm{~mm}$ long $\times 1 \mathrm{~mm}$ diameter contact wire electrodes. The distance between the electrodes is $4 \mathrm{~mm}$.

A Square wave unipolar pulse train is delivered by a voltage pulse generator (ELECTRO cell B10 Betatech, St Orens, France) (see troubleshooting 5).

The proper delivery of the pulses from the pulse generator is monitored on-line on the touch screen. A current-clamp with a wide bandwidth (Chauvin Arnoux, Paris, France) connected to a digitizer (Picoscope, St Neots, UK) is used to register the delivered current profiles. The monitoring of both the voltage and the delivered current allows a perfect control of the electrical operating conditions and the reproducibility of the procedures. All data are stored on-line on a PC labtop to keep an accurate follow-up of the experiments (see troubleshooting 6). 
A mixed (HV-MV) train of electric pulses is delivered. High Voltage (HV) pulse consists in $100 \mu \mathrm{s}$ square waved pulses of $400 \mathrm{~V}$ followed by Medium Voltage (MV) pulse that is $20 \mathrm{~ms}$ square waved pulse of $100 \mathrm{~V}$. The intermediate time delay was $50 \mathrm{~ms}$. Pulses in the train are applied at the frequency of $1 \mathrm{~Hz} .4$ successive pulses are present in the train. All these settings are selected from the pulse generator (Fig.2).

Muscle contractions are observed along each pulse of the train ( 4 along the procedure) (see troubleshooting 7).

Remove the mask for isoflurane from the mouse nose and observe the animal until it has fully recovered from anesthesia (see troubleshooting 8). Anesthesia lasts only 2-3 min.

Clean the electrodes with ethanol $70 \%$.

Pulses are delivered at only one injection site. The second is used as a control of the lack of expression when the plasmid is only injected.

\section{Expression}

Shave and depilate the mice to avoid the auto-fluorescence of the hair.

Maintained the mice under isofluorane anesthesia during the imaging procedure.

Expression of fluorescent proteins is detected in vivo by fluorescence imaging (Macrofluo microscope (Leica, Wetzlar, Germany) equipped with a cooled CCD camera (Roper Coolsnap HQ, Photometrics, Tucson, AZ) using the 0.57 magnification).

The exposure time is set at $1 \mathrm{~s}$ with no binning.

Color imaging is obtained by use of CRI Micro*Color 2 Liquid Crystal Technology. The fluorescence excitation is obtained with an EL6000 light source (Leica, Wetzlar, Germany) and the ET $\mathrm{mCH} / \mathrm{TR}(\lambda \mathrm{ex}=560 / 40 \mathrm{~nm}, \lambda \mathrm{em}=630 / 75 \mathrm{~nm}$ ) filter sets (Chroma technology, Rockingham, USA). This procedure allows analysis of vector expression on the same animal during several weeks. 
For images acquisition and quantification, the MetaVue5.2 software (Universal, Downingtown, PA, USA) is used. Images are processed for contrast and brightness. Highresolution images of $1392 \times 1040$ pixels are captured directly on a Dell PC.

Imaging is observed during 20 days after the treatment. Expression (fluorescence emission in the red) is detected after 2 days and peaks at 8 days (see troubleshooting 9).

A quantitative analysis is obtained from the digitized images. We use the NIH Image J software. Processing is obtained on the red channel of the RGB image. Expression (fluorescence emission) is observed only in the tissue present between the electrodes. The profile reflects the distribution of the injected solution where a bleb is obtained and confirms the expected field distribution (Fig.4) (see troubleshooting 10).

No fluorescence is observed at the injection site where no pulses are delivered

\section{Histology}

At day 0 and day 7 post-treatment, the mice were sacrificed,

The region of the skin exposed to the treatment was excised with a scalpel. At D0, samples were collected $3 \mathrm{~h}$ after GET or PBS injection.

Samples were fixed $24 \mathrm{H}$ in $10 \%$ neutral buffered formalin and then stored in $70 \%$ ethanol After deshydratation, skin was embedded in paraffin.

$5 \mu \mathrm{m}$ thick sections were cut in the direction perpendicular to the skin layers.

After rehydratation, staining with hematoxylin and eosin was performed.

The samples were mounted in Eukkit medium (Sigma).

Observation was performed with a scanner (Pannoramic 250, 3DHISTECH) (Fig.5) 
TROUBLESHOOTINGS

1. The thickness of the skin is variable between animals according to their age and sexe; this affect the field distribution and as a result the topology of expression. Avoid fat (male) animals ${ }^{19}$.

2. tdTomato plasmid codes for a protein with an emission in the red (wavelength longer than $630 \mathrm{~nm}$ ). Its expression is easily detected as its spectral range is in skin optical window, where light scattering and absorption are limited and do not alter the detection of the emission ${ }^{20}$. Td Tomato fluorescence is photostable; its absorption coefficient is high as well as its quantum yield ${ }^{21}$.

3. This step needs practice. ID injection in mice skin has been described for RNA (22). A similar procedure was adapted for pDNA injection in female mice with the appropriated needle. One should be careful in the speed of injection, that must be proceeded in a 5-7 $\mathrm{s}$ duration. The formation of the bleb and its observation are very important as they tell us when the pDNA is present and is a guide for positioning the parallel electrodes (Fig.3). The proper ID delivery of the pDNA is shown by a whitening of the skin where the needle is present. No leak of the solution should be observed. A delay between the $25 \mu$ injection and the removal of the needle should be observed to obtain a decrease in the pressure induced by the injected volume in the skin.

4. The conducting gel is needed to obtain that the electrical contact with the skin is present to make sure that the current will flow in the tissue ${ }^{18}$. It should be present all along the electrodes to get the expected field distribution in the tissue. Be careful to clean any trace of gel present on the skin between the two electrodes and linking them. This will build a short circuit and the current will be only along the skin surface and would not penetrate in the tissue. No muscle contraction will be observed and the current will be high. 
5. Other pulse generators can be used. The IGEA "cliniporator" and the BTX "Agile pulse" with the "Pulse Agile" technology can deliver the pulse sequence similar to that was used with the B10 electropulsator (2 $0.05 \mathrm{~ms} \mathrm{HV}$ rather than a single $0.1 \mathrm{~ms}$ with the BTX generator).

6- This is achievable with the 3 pulse generators mentioned in Trouble shooting 5 with either a direct display or by transfer with an USB key of a CSV file.

7. The proper pulse delivery is shown both by the current transient and the muscle contraction.

8. As the body temperature is observed to decrease along anesthesia, one should either place a heating lamp above the animal or keep the mouse on a heating blanket to ensure successful recovery.

9. A more sustained expression would be obtained by using minicircle plasmid vectors ${ }^{23}$, 24.

10. This confirms that the injection step is critical for a high level in expression.

\section{CONCLUSION}

This protocol is effective with different reporter gene coding plasmids (GFP, minicircles, $\mathrm{PgP}$ rich and free constructs). A large surface of the skin is showing a rather homogeneous expression. The long-lived expression suggests that the thin layer of subdermal striated muscle (panniculus carnosus) is affected, a contribution of the MV pulse $\mathrm{e}^{25}$. This confirms the Comsol simulation ${ }^{17}$ where the field affects all skin layers as with minimally invasive electroporation device ${ }^{6}$. The treatment is very fast as the train of pulses is delivered in $3 \mathrm{~s}$. No deleterious effect is observed. Present investigations confirm its potentiality for transient effects of expression of clinically relevant plasmids coding for IL12. 
ACKNOWLEGMENTS

Supported by grants of the Region Midi-Pyrénées (recherche en transfert clinique, normalisation, et innovation interdisciplinaire en biosanté $n^{\circ} 11052700$ et $n^{\circ} 13050740$ ) and of the EU FP7 Oncomirs (Grant 201102). We thank the "Toulouse Réseau Imagerie" and "Anexplo" core IPBS facilities (Genotoul, Toulouse, France). Research was conducted in the scope of the EBAM European Associated Laboratory (LEA)

Author Contributions: LP designed, performed the biological experiments and contributed in writing the paper; SC designed and performed the biological experiments; EB performed the animal imaging and contributed in writing the paper; MPR contributed in writing the paper; JT and MG designed the main concepts of the experimental work, checked the results and wrote the manuscript.

\section{AUTHOR DISCLOSURE STATEMENT}

No competing financial interests exist 


\section{REFERENCES}

1 Gothelf A, Gehl J, Gene Electrotransfer to Skin; Review of Existing Literature and Clinical Perspectives, Curr Gene Ther 2010 ;10: 287-299.

2 Kupper TS, Fuhlbrigge RC, Immune surveillance in the skin: Mechanisms and clinical consequences, Nat Rev Immunol 2004; 4 : 211-222.

3 Ulmer JB, Montgomery DL, Tang AM et al. DNA vaccines against tuberculosis, Novart Fdn Symp, 1998; $217: 239-253 .$.

4 Choi MJ, Maibach HI, Topical vaccination of DNA antigens: Topical delivery of DNA antigens, Skin Pharmacol Appl, 2003; 16: 271-282

5 Morris DL, Cho KW, Delproposto JL, et al. Adipose tissue macrophages function as antigen-presenting cells and regulate adipose tissue CD4+ T cells in mice. Diabetes 2013; 62: $2762-2772$

6 Amante DH, Smith TRF, Mendoza JM, et al. Skin transfection patterns and expression kinetics of electroporation-enhanced plasmid delivery using the CELLECTRA-3P, a portable next-generation dermal electroporation device. Hum Gene Ther Methods 2015; 26: 134146.

7 Brave A, Nystrom S, Roos AK, et al, Plasmid DNA vaccination using skin electroporation promotes poly-functional CD4 T-cell responses, Immunol Cell Biol, 2011; 89 : 492-496.

8 Vandermeulen G, Staes E, Vanderhaeghen ML, et al. Optimisation of intradermal DNA electrotransfer for immunisation, J Control Release 2007; 124 :81-87.

9 Golzio M, Teissie J, Rols MP, Direct visualization at the single-cell level of electrically mediated gene delivery, P Natl Acad Sci USA 2002; 99 : 1292-1297.

10 D. Miklavcic D, K. Beravs K, D. Semrov D, et al. The importance of electric field distribution for effective in vivo electroporation of tissues, Biophys J 1998; 74 : 2152-2158. 
11 Satkauskas S, Bureau MF, Puc M, et al. Mechanisms of in vivo DNA electrotransfer: Respective contributions of cell electropermeabilization and DNA electrophoresis, Mol Ther 2002; 5 :133-140.

12 Chizmadzhev YA, Indenbom AV, Kuzmin PI, et al. Electrical properties of skin at moderate voltages: contribution of appendageal macropores. Biophys J 1998; 74: 843-856

13 Pavselj N, Preat V, Miklavcic D, A numerical model of skin electropermeabilization based on In vivo experiments, Ann Biomed Eng 2007; 35 : 2138-2144

14 Daugimont L, Baron N, Vandermeulen G, et al, Hollow Microneedle Arrays for Intradermal Drug Delivery and DNA Electroporation, J Membrane Biol 2010; 236 : 117125.;

15 Kos S, Vanvarenberg K, Dolinsek T, et al. Gene electrotransfer into skin using noninvasive multi-electrode array for vaccination and wound healing, Bioelectrochemistry 2017; $114: 33-41$.

16 Heller R., Cruz Y, Heller LC et al. Electrically Mediated Delivery of Plasmid DNA to the Skin, Using a Multielectrode Array, Hum Gene Ther 2010; 21 (:357-362.

17 Mazères S, Sel D, Golzio M, et al. Non invasive contact electrodes for in vivo localized cutaneous electropulsation and associated drug and nucleic acid delivery. J Control Release. 2009 ;134(2):125-31. doi: 10.1016/j.jconrel.2008.11.003.

18 Pedron-Mazoyer S, Plouët J, Hellaudais L, et al. New anti angiogenesis developments through electro-immunization: optimization by in vivo optical imaging of intradermal electro gene transfer. Biochim Biophys Acta. 2007 ;1770(1):137-42..

19 Azzi L, El-Alfy M, Martel C, et al Gender differences in mouse skin morphology and specific effects of sex steroids and dehydroepiandrosterone. J Invest Dermatol. 2005 ;124(1):22-7

20 Sabino CP, Deana AM, Yoshimura TM, et al. The optical properties of mouse skin in the visible and near infrared spectral regions.J Photochem Photobiol B. 2016 ;160:72-8. doi: 10.1016/j.jphotobiol.2016.03.047 
21 Shaner NC, Steinbach PA, Tsien RY A guide to choosing fluorescent proteins. Nat Methods. $2005 ; 2(12): 905-9$

22 Electroporation Protocols: Preclinical and Clinical Gene Medicine (2014) Li, S., Cutrera, J., Heller, R., Teissie, J. (Eds.), Springer

23 Marie C, Vandermeulen G, Quiviger M, et al. pFARs, plasmids free of antibiotic resistance markers, display high-level transgene expression in muscle, skin and tumour cells. J Gene Med. 2010 ; 12(4):323-32. doi: 10.1002/jgm.1441.

24 Chabot S, Golzio M, Teissie J Tissue-targeted gene electrodelivery of minicircle DNA in minicircle and miniplasmid expression vectors (2013), pp.203-213 Ed Schleef M, Wiley 25 Kos S, Blagus T, Maja Cemazar M, et al Electrotransfer parameters as a tool for controlled and targeted gene expression in skin Molecular Therapy-Nucleic Acids $2016 ; 5$, e356; doi:10.1038/mtna.2016.65 


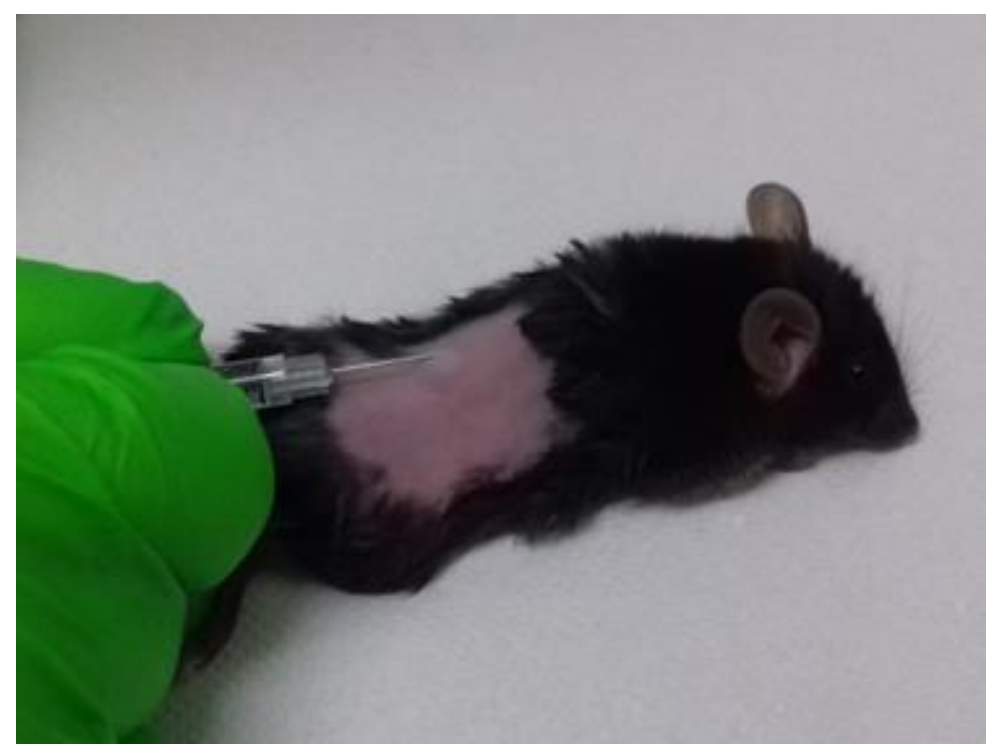

Figure 1: Visualization of the injection point. Mice were injected i.d. in two sites with $25 \mu \mathrm{l}$ of a $1 \mathrm{mg} / \mathrm{ml}$ DNA plasmid solution. A bleb on the skin is present at each injection site 

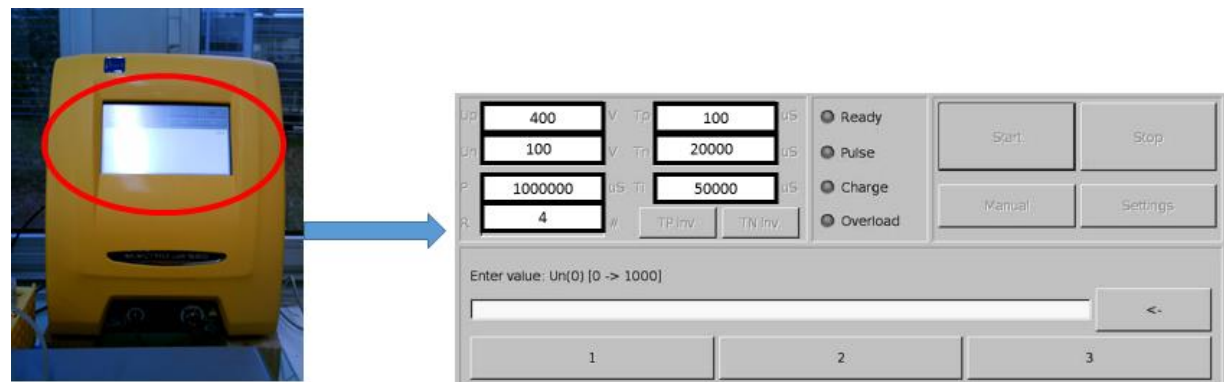

Enter value Un(0) $\{0 \rightarrow 1000\}$
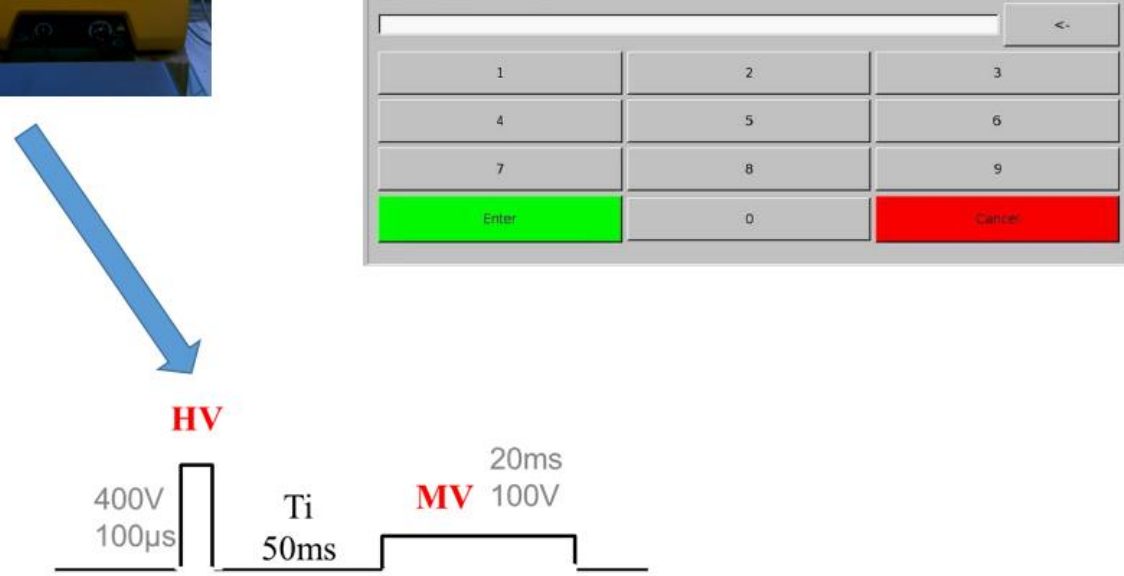

Fig.2 Settings the parameters on the B10 touch-keyboard

By using of the touch screen (inside the red circle ), the proper pulse parameters (durations $\mathrm{T}$, voltages $\mathrm{U}$, interval between the pulses $\mathrm{Ti}$, delay in the train $\mathrm{P}$, number of pulses $\mathrm{R}$ ) are set (as shown on the right to obtain the HVMV pulse displayed on the lower part of the figure. 


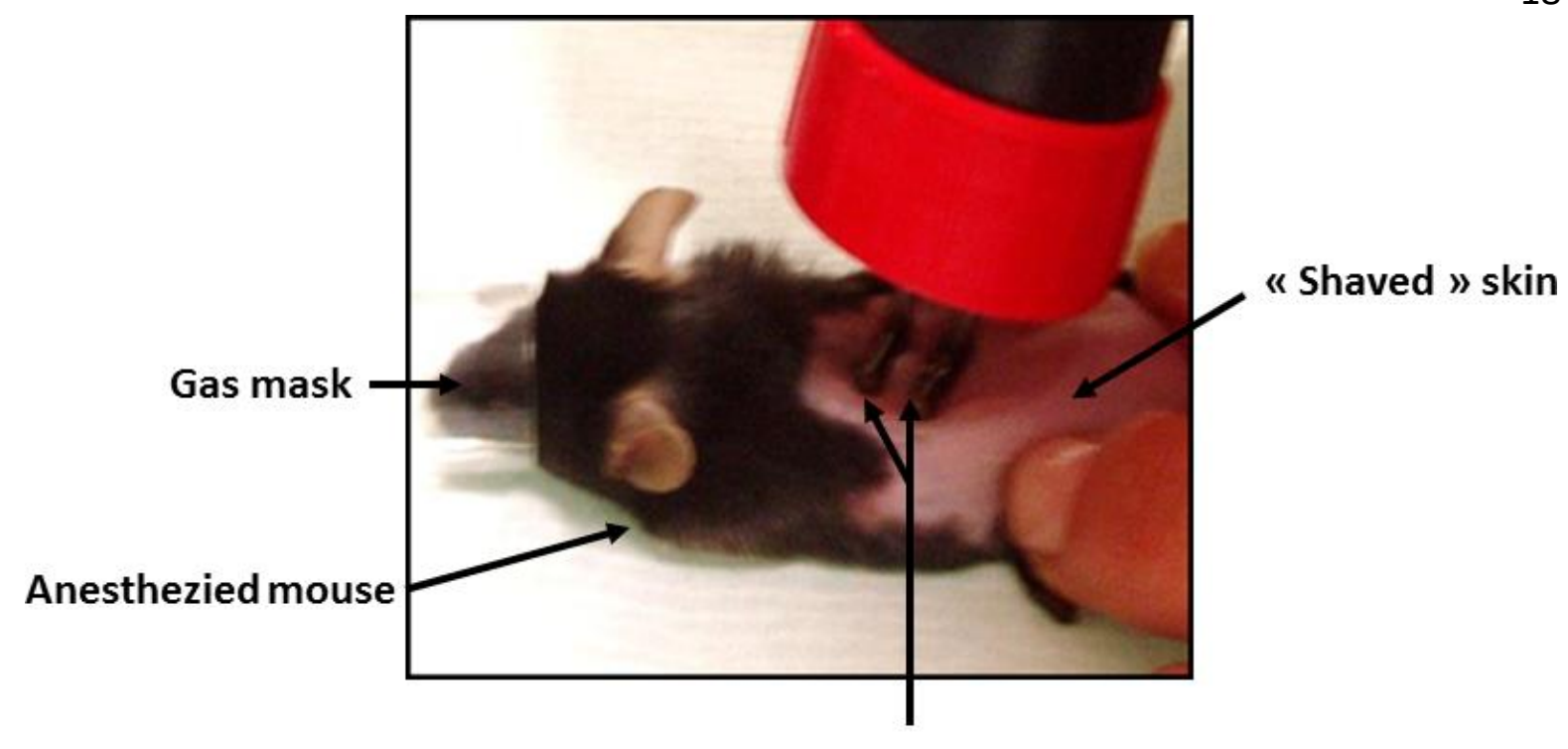

Contact electrodes

Fig.3 Contact electrodes covered with the conducting gel are brought in firm contact with the "shaved" skin of the mouse overlapping the bleb due to the plasmid injection 


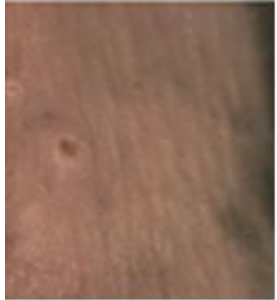

Direct light

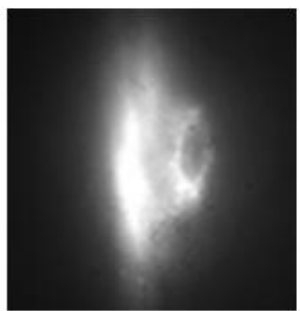

red fluorescence

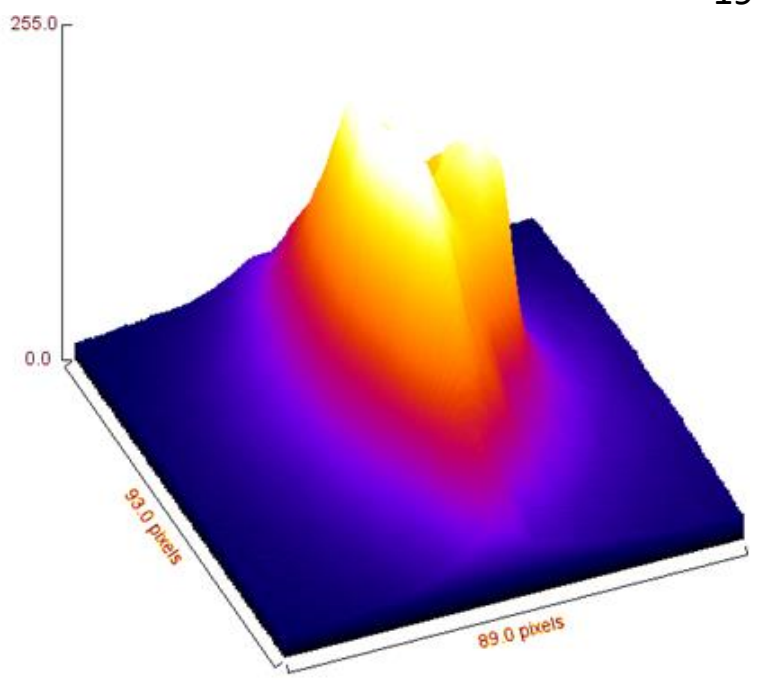

Surface plot

Fig.4 Imaging of dt Tomato expression after skin GET 8 days after the treatment

No skin damage is observed by the direct light observation. The fluorescent image in the red wavelength is the expression of the gene $($ size $1 \mathrm{~cm} \times 1 \mathrm{~cm})$. Image analysis gives quantitative results in pseudo-colour. 


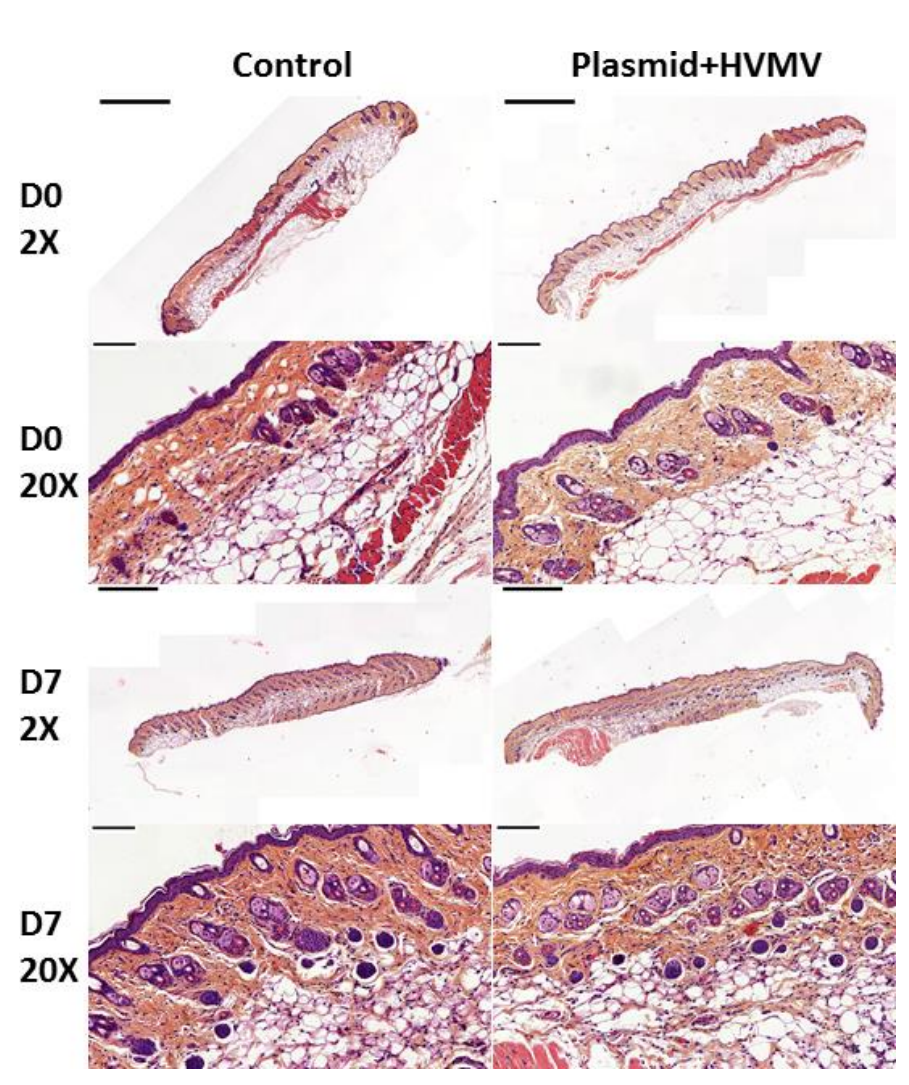

Fig.5 Histological images

Representative eosin/hematoxylin images, at days 0 and 7, of control skin only injected with PBS (left) and skin electropermeabilized with HVMV pulses in presence of plasmid (right).

Scale bars : $1 \mathrm{~mm}$ for $2 \mathrm{X}$ images and $100 \mu \mathrm{m}$ for $20 \mathrm{X}$ images. 